\title{
Reducing recurrent stroke: Methodology of the motivational interviewing in stroke (MIST) randomized clinical trial
}

\author{
Rita Krishnamurthi', Emma Witt ${ }^{1}$, Suzanne Barker-Collo², Kathryn McPherson ${ }^{3}$, \\ Kelly Davis-Martin ${ }^{1,4}$, Derrick Bennett ${ }^{5}$, Elaine Rush ${ }^{6}$, Flora Suh', Nicola Starkey ${ }^{7}$, \\ Varsha Parag ${ }^{8}$, Yogini Rathnasabapathy ${ }^{9}$, Amy Jones ${ }^{1}$, Paul Brown ${ }^{10}$, Braden Te Ao', and \\ Valery L. Feigin ${ }^{1} *$ on behalf of the ARCOS IV Programme Group
}

\begin{abstract}
Rationale Recurrent stroke is prevalent in both developed and developing countries, contributing significantly to disability and death. Recurrent stroke rates can be reduced by adequate risk factor management. However, adherence to prescribed medications and lifestyle changes recommended by physicians at discharge after stroke is poor, leading to a large number of preventable recurrent strokes. Using behavior change methods such as Motivational Interviewing early after stroke occurrence has the potential to prevent recurrent stroke.

Aims and/or hypothesis The overall aim of the study is to determine the effectiveness of motivational interviewing in improving adherence to medication and lifestyle changes recommended by treating physicians at and after hospital discharge in stroke patients $\mathbf{1 2}$ months poststroke to reduce risk factors for recurrent stroke.

Design Recruitment of $\mathbf{4 3 0}$ first-ever stroke participants will occur in the Auckland and Waikato regions. Randomization will be to intervention or usual care groups. Participants randomized to intervention will receive four motivational interviews and five follow-up assessments over 12 months. Nonintervention participants will be assessed at the same time points.
\end{abstract}

Study outcomes Primary outcome measures are changes in systolic blood pressure and low-density lipoprotein levels 12

Correspondence: Valery L Feigin*, National Institute for Stroke and Applied Neurosciences, School of Rehabilitation and Occupation Studies, School of Public Health and Psychosocial Studies, Faculty of Health and Environmental Studies, AUT University, AUT North Shore Campus, AA254, 90 Akoranga Dr, Northcote 0627, Private Bag 92006, Auckland 1142, New Zealand.

E-mail: valery.feigin@aut.ac.nz

${ }^{1}$ National Institute for Stroke and Applied Neurosciences, Faculty of Health and Environmental Sciences, Auckland University of Technology, Auckland, New Zealand

${ }^{2}$ Department of Psychology, University of Auckland, Auckland, New Zealand

${ }^{3}$ Person-Centered Rehabilitation Centre, Faculty of Health and Environmental Sciences, Auckland University of Technology, Auckland, New Zealand

${ }^{4}$ Harvard Institute of Coaching, Mclean Hospital, Harvard University, Boston, MA, USA

${ }^{5}$ Clinical Trial Service Unit and Epidemiological Studies Unit, Nuffield Department of Clinical Medicine, University of Oxford, Oxford, UK

${ }^{6}$ Faculty of Health and Environmental Sciences, Auckland University of Technology, Auckland, New Zealand

${ }^{7}$ Department of Psychology, Waikato University, Hamilton, New Zealand ${ }^{8}$ National Institute for Health Innovation, University of Auckland, New Zealand

${ }^{9}$ Waitemata District Health Board, North Shore Hospital, Auckland, New Zealand

${ }^{10}$ School of Social Sciences, Humanities and Arts, University of California, Merced, CA, USA

DOI: $10.1111 /$ ijs.12107 months poststroke. Secondary outcomes include self-reported adherence and barriers to prescribed medications, new cardiovascular events (including stroke), changes in quality of life, and mood.

Discussion The results of the motivational interviewing in stroke trial will add to our understanding of whether motivational interviewing may be potentially beneficial in the management of stroke and other diseases where similar lifestyle factors or medication adherence are relevant.

Key words: adherence, motivational interviewing, recurrent stroke, secondary prevention

\section{Introduction}

Strokes recur in $6-25 \%$ of people (1-3), usually in the first year $(1,4,5)$. The risk of stroke is highest early after the event (4). By five-years poststroke, the cumulative risk of recurrent stroke is $30-40 \%$ (5). Recurrent stroke may lead to greater disability, institutionalization, increased risk of dementia, and a high risk of death (6), and therefore, poorer health and economic outcomes (7).

Management strategies for secondary stroke prevention are well established $(2,3,5,7-10)$, yet remain underutilized $(8,11)$. The landmark INTERSTROKE studies suggest that 10 risk factors are associated with $90 \%$ of the risk of first-ever stroke (12). Recurrent strokes are largely preventable using similar strategies to that of primary stroke prevention (13). Several trials have attempted to improve secondary prevention of stroke and coronary heart disease through education of patients and/or caregivers $(14,15)$ and improving access to care (16-20). However, these have not improved management of clinical or behavioral risk factors (14$19,21,22)$, required complex computer systems (20), or were designed for inpatients only $(21,22)$. In a systematic review, lifestyle modifications were shown to be effective for secondary stroke prevention with improvements seen in both lifestyle behavior changes and physiological outcomes (23). A recent study suggests that long-term adherence to nonspecific prescription pills reduced the risk of subsequent vascular events in persons who had a recent ischemic stroke (24). Although adherence to prescribed medications and/or recommendations to lifestyle changes (such as reducing smoking, increasing physical activity) after first stroke are effective strategies to reduce recurrent stroke, in practice, the implementation of these recommendations is poor $(25,26)$. Targeting adherence may be a key to reducing the incidence of recurrent stroke; therefore, it is both appropriate and timely to conduct trials to assess whether new approaches may 
improve patient adherence to evidence-based guidelines for secondary stroke prevention $(10,27)$ after hospital discharge.

Motivational interviewing (MI) is a structured, patient-focused (28-33), and cost-effective (34) intervention that was originally developed for the treatment of people with problem drinking, addictions (35,36), and substance abuse management (32,37-40) but has been increasingly used in other areas of medicine $(41,42)$, including stroke (43-47), traumatic brain injury (48), and cardiovascular disease (49-51). The objective of MI is to help the client to explore their ambivalence towards behavior change, and by resolving this ambivalence, facilitating positive behavior change in the individual (42).

A significant benefit of MI on mood early after stroke over usual stroke care was recently demonstrated in a randomized controlled trial (43). Given the evidence for efficacy and cost effectiveness of MI for behaviour change, this intervention has been identified as a high research priority $(41,52)$. However, the majority of trials have been relatively small and no studies have been carried out specifically to test the effectiveness of MI in reducing risk factors related to recurrent stroke. Therefore, a large randomized clinical trial is needed to provide clarity on how MI applies to recurrent stroke. Given its potential to encourage patients to adhere to medication and lifestyle changes recommended by clinicians, this trial is designed to assess the effectiveness of MI in reducing outcomes related to recurrent stroke.

\section{Objectives}

The overall aim of the study is to determine the effectiveness of MI in improving adherence to medication and lifestyle changes recommended by treating physicians at and after hospital discharge in stroke patients 12 months postrandomization.

\section{Methods}

\section{Trial design}

This is a phase III single-blind randomized controlled trial of participants with first-ever stroke (excluding subarachnoid haemorrhage) followed for 12 months after randomization. Participants are randomized to either the MI intervention group (henceforth referred to as MI) or usual care (UC). Recruitment for the trial commenced on March 1, 2011 with the populationbased ARCOS IV Incidence and Outcomes Study (53). Figure 1 is a flowchart of the overall trial design of the MIST study.

\section{Patient population- inclusion and exclusion criteria}

All consecutive adult (16 years or older) stroke survivors who had a first-ever stroke and are residents of Auckland or Waikato Region are considered potentially eligible for inclusion in the trial. Stroke is defined according to the World Health Organization definition as 'rapidly developing clinical signs of focal (or global) disturbance of cerebral function, with symptoms lasting 24 hours or longer or leading to death, with no apparent cause other than of vascular origin' (54). A diagnostic review committee comprising four stroke neurologists meet fortnightly to confirm the diagnosis of stroke and classification of all ischemic cases. The committee uses medical history, hospital discharge summaries, clinical and laboratory findings (including vascular and cardiac imaging), or necropsy results when available to inform their deci- sions. A detailed description of the diagnostic review process is available in the article describing the methodology of the ARCOS IV Incidence and Outcomes Study (53).

The main exclusion criteria are (1) recurrent stroke (excluding clinically silent previous strokes); (2) a diagnosis of subarachnoid haemorrhage; (3) significant impairments precluding participation (e.g. aphasia); (4) inability to give informed consent; (5) another condition likely to impact their participation in the trial (e.g. life-threatening condition other than cardiovascular disease); and (6) expected discharge to hospital/nursing home setting where adherence to lifestyle recommendations and medications is beyond participant control.

\section{Ethical approval and trial registration}

The study was given ethical approval by the Northern X Regional Ethics Committee for experiments in human subjects and the Auckland University of Technology Ethics Committee. The trial is registered with the Australian New Zealand Clinical Trial Registry (Trial Registration Number: ACTRN 12610000715077).

\section{Recruitment}

Between March 1, 2011 and February 29, 2012, potential participants were recruited for the trial from the main ARCOS IV Incidence and Outcomes study (53). Participants eligible for ARCOS IV were approached for participation in the MIST study during the period of recruitment for ARCOS incidence study. Additional participants were recruited from the Waikato region for the same period. From March 1, 2012, participants will be recruited from all four Auckland public hospitals, and the recruitment period is expected to continue up to December 2013. Daily searches of admissions data are carried out in all four Auckland region public hospitals for records suggestive of a diagnosis of first-ever stroke.

\section{Informed consent}

Potentially eligible participants are identified by a hospital-based research assistant (RA) via regular checks of each hospital database for new admissions and participation at weekly medical and diagnostic team meetings for relevant hospital wards/units. Potential participants are approached by an RA to give informed consent to participate. If consent is obtained, baseline case record forms (CRFs) will be completed.

\section{Screening}

All participants who meet the main inclusion criteria and provide informed consent undergo a face-to-face detailed screening process with a study RA to ensure that they meet the eligibility criteria for randomization into the trial. Table 1 shows the eligibility screening criteria used to identify participants eligible for randomization. Information from medical records is also used when available to aid the screening process. After completion of eligibility screening, participants identified as meeting the eligibility criteria are randomized.

\section{Randomization}

Eligible study participants are randomized to either the MI or UC groups using web-based computerized randomization software. A stratified minimization algorithm is used to randomize participants in order to balance possible prognostic factors [i.e. age $(<70$, 


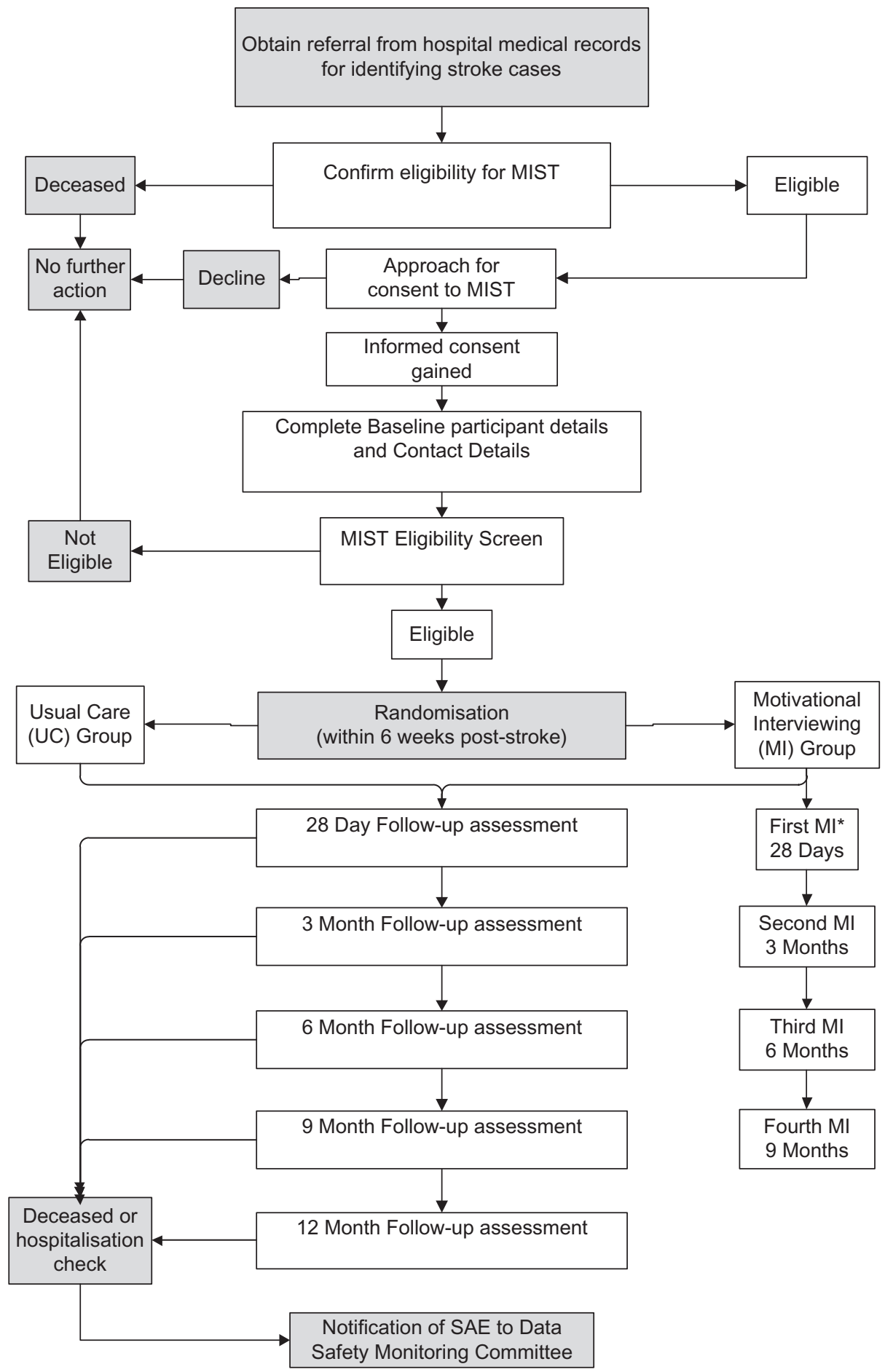

Note: all time frames are in months post-stroke ${ }^{*}$ Ml: Motivational Interviewing

Fig. 1 Flowchart of motivational interviewing in stroke (MIST) study procedures.

$70+$ ), stroke severity (Barthel Index $<18$ and $\geq 18$ ), gender and race-ethnicity (European, non-European)] across the two groups.

Following randomization, a confirmation letter is sent to the study participant that includes a reminder of the timing of primary outcome measures requested for the purpose of the study (blood pressure and blood lipid cholesterol levels at 12 months after stroke). A reminder letter is also sent to the participant, along with a blood request form for a free blood lipid test, one-month prior to the 12 month assessment date. In addition, a letter is sent to the participant's General Physician (GP) to inform them of their patients' participation in the trial and as a reminder of the New Zealand Clinical Guidelines for Stroke Management recommendations to routinely monitor blood pressure and blood lipid levels in stroke patients. The letter includes a request for access to 
Table 1 Eligibility screening criteria

\begin{tabular}{ll}
\hline Criteria & Eligibility requirement for inclusion \\
\hline Diagnosis & First-ever stroke, not subarachnoid hemorrhage \\
Date of stroke & Randomization within six-weeks poststroke \\
Cognitive impairment & Mini-Mental State Examination $(55) \geq 23$ \\
Mental Health & No current mental health diagnosis and/or receiving current psychological treatment that would affect/contradict \\
& motivational interviewing \\
Involvement in other studies? & No involvement in another study that could affect compliance with treatment or result in significant participant \\
& burden \\
Access to telephone & Has telephone access \\
Availability & Available to answer further questions in up to 12 months postrandomization \\
English language & Able to converse fluently in English \\
\hline
\end{tabular}

these measures by our research team at relevant study time points if required.

\section{Blinding}

To reduce measurement bias, follow-up assessments are carried out by individual community-based RAs who are blind to the treatment allocation of the participant and not involved in the delivery of the intervention. At the time of recruitment to the study and prior to each follow-up assessment, study participants are requested not to disclose their group allocation by mentioning any contact with the motivational interviewer to the RA conducting the assessment. Compliance to group allocation blinding will be monitored by the study manager, and reports of unblinding either by participants or research assistants will be recorded as protocol violations, and steps are taken to ensure future assessments are conducted by a blinded assessor for any unblended participants.

\section{MI intervention}

The trial intervention is based on the principles of $\mathrm{MI}$ as described by Miller and Rollnick (32). To assist the interviewers in adhering to a standardized approach and format when conducting the intervention, an intervention manual has been developed providing guidance for each of the intervention time points and appropriate tools to assist in the interviewing process.

MI interviews are conducted at 28 days, three-, six-, and ninemonths poststroke (see flowchart Fig. 1). The first interview is conducted individually face to face. Subsequent interviews are conducted over the telephone whenever possible. MI interviews are to be conducted by an RA who has undergone training in MI and has an understanding of good clinical practice in research. Researchers conducting the interventions are provided with training on the principles of MI by an experienced trainer who is able to demonstrate relevant experience and expertise in this area. RAs were additionally provided training on stroke risk factors, such as diet and nutrition, and medications. As per principles of MI, standard information on cardiovascular disease risk and prevention from the New Zealand Heart Foundation was provided to participants only at their request. Ongoing training and feedback are provided to the MI interviewers throughout the study at regular group and individual training sessions. All training material is saved electronically for future reference. Interviews conducted with participants are recorded, and the de-identified electronic files are available for review by the interviewers and trainer. Ongoing monitoring of the quality and consistency of the MI across all RAs is regularly provided by the MI trainer.

\section{Primary outcomes}

Primary outcome measures are (1) change in systolic blood pressure (SBP) and (2) low-density lipoprotein (LDL)-cholesterol levels at 12 months poststroke.

\section{Secondary outcomes}

Secondary outcome measures are (1) self-reported adherence to prescribed medications, including self-reported use of antiplatelet/anticoagulant medications, statin, and blood pressure-lowering therapy medications as prescribed (and crosschecked with electronic medication dispense records, where available); (2) self-reported barriers to adherence to medications; (3) cardiovascular events (new stroke or coronary heart disease, both fatal and nonfatal); (4) quality of life as measured by the SF-36 (56); (5) mood as measured by the Hospital Anxiety and Depression Scale (57); (6) change in other blood lipid levels (HDL-cholesterol, total cholesterol, and triglycerides); (7) physical disability as measured by the Barthel Index (58) at 12 months; and (8) healthcare resource consumption and cost effectiveness of the intervention.

Outcome assessments (Table 2) are carried out at 28 days, three-, six-, nine- and 12 months following stroke, with the primary outcome assessment for SBP and LDL-cholesterol carried out at 12 months poststroke. Blood pressure measurements are carried out at six- and 12-month assessments at the participants' place of residence.

\section{Withdrawals and loss to follow-up}

Participants are able to withdraw their involvement in the study at any time. The 'intention-to-treat' principle will apply for participants who withdraw from the study or are lost to follow-up, so that data from up to and including their last completed assessment will be included in the analyses.

\section{Data management}

Data management services including statistical analyses are contracted to the National Institute for Health Innovation, The University of Auckland. De-identified participant details and data from CRFs are entered into a web-based password-protected database managed by the data management team. All participants 
Table 2 Outcome measures and timing of follow-up

Baseline* Three-months Six-months Nine-months 12 months

From medical notes:

Demographics (e.g. age, race-ethnicity)

Type of stroke, stroke severity

Prestroke lifestyle risk factors (e.g. smoking, physical activity)

Medical/cardiovascular history

Blood lipid profile

Blood pressure

Telephone interview

Short Form-36 (SF-36)

Barthel Index (BI)

Hospital Anxiety Depression Scale (HADs)

Costs (direct healthcare expenditures)

Self-reported adherence and barriers to prescribed medications

Modification of lifestyle risk factors

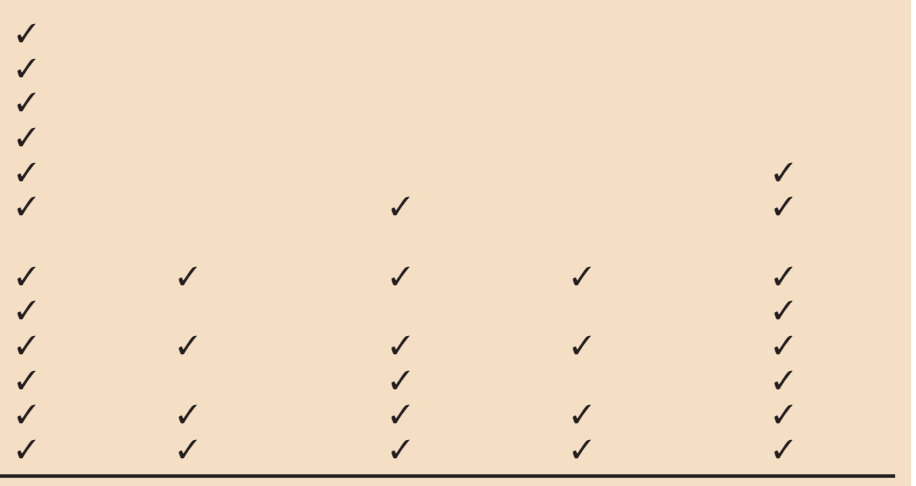

*Baseline assessments are carried out at 28 days poststroke.

in the study are allocated a unique registration number electronically generated by the database. Paper copies of CRFs and any supporting documentation (including hospital discharge summaries and other relevant medical reports) are de-identified and stored securely, with identifying contact details and signed consent forms stored separately, for seven-years.

\section{Data safety monitoring}

An independent Data Safety Monitoring Committee (DSMC) has been established to safeguard the interests of the trial participants, assess the safety and efficacy of the intervention during the trial, and monitor the overall conduct of the clinical trial. The DSMC provides recommendations about stopping or continuing the trial in the event of harm or undue risk to study participants. The DSMC may also make recommendations relating to the recruitment or management of participants, improving adherence to good clinical practice and procedures for data management and quality control. The DSMC group meets on an annual basis or more frequently if the need arises.

\section{Sample size}

Four hundred and thirty participants are required to provide $85 \%$ power at $\alpha=0.05$ (two sided) to detect a $0.25 \mathrm{mmol} / \mathrm{l}$ difference in LDL-cholesterol (SD $0.8 \mathrm{mmol} / \mathrm{l}$ ), and $80 \%$ power to detect a $4 \mathrm{mmHg}$ difference in SBP (SD $14 \mathrm{mmHg}$ ), respectively, between UC and MI groups, assuming 10\% loss to follow-up.

\section{Statistical analyses}

All statistical analyses will be performed using sas version $9 \cdot 3$ (SAS Institute Inc., Cary, NC). All tests of significance will be two tailed and at 5\% significance level throughout the analyses. Baseline characteristics will be summarized and descriptive summary statistics provided for each treatment group. The distribution of all continuous outcomes will be assessed for normality, and skewed data will be subjected to an appropriate transformation before analysis. Continuous data will be analyzed using multiple linear regression if normally distributed and nonparametric analysis if not normally distributed. The change from baseline in each of the repeated continuous outcomes will be analyzed using mixed models and adjusted for baseline value and covariates such as presence of depression as appropriate. Simple incidence rates, relative and absolute risks, and their respective 95\% confidence intervals will be calculated for all binary outcomes, and the treatment groups will be compared using chi-squared tests with multiple logistic regression analysis adjusting for other variables as appropriate. In order to check the validity of the missing at random (MAR) assumption, baseline characteristics of those participants with available data and those participants missing data will be compared. The primary analyses will be carried out on an intention to treat basis and mixed models are robust to data that are MAR (55). A per-protocol analysis will be performed to check the robustness of the results where participants with any major protocol violations such as cross-over treatments, withdrawals, and lost to follow-up will be excluded. The consistency of effects for major ethnic subgroups (Māori, Pacific Island, New Zealand Europeans) will also be assessed using tests for heterogeneity.

\section{Cost effectiveness}

The cost effectiveness of the study will be determined by comparing the costs and outcomes associated with the control group with the group provided with MI. The costs will include the direct healthcare costs (e.g. hospitalizations, rehabilitation, primary care and outpatient visits, home help and support, and medications). Information on health service utilization is being measured through patient questionnaires and electronic data sources (e.g. medical databases such as the Patient Management System, Accident Compensation Corporation, and Ministry of Health databases matched by individual National Health Index number). In addition, the cost of delivering the intervention will be monitored using a resource-based costing approach that measures the inputs required to deliver the program (e.g. identify time required to recruit, prepare, and deliver the programme, time required to coordinate the care with other providers, distance travelled to deliver the program, etc) and then applying market prices to each of these resources (e.g. cost per hour for the therapist including $50 \%$ overheads). This will provide an estimate not only of the net costs associated with the intervention, but also the cost to other organizations interested in adopting MI as part of their standard practice. 
Because the intervention is ultimately aimed at reducing the risk of stroke recurrence, the primary outcome variable will be the Quality Adjusted Life Years associated with patients in each arm of the study. Utility scores will be assessed using the EuroQOL 5D, and economic modeling using a Markov Modelling in (TreeAge Pro Suite) 2012 software (TreeAge Software Inc, Williamstown, MA) will estimate the incremental cost effectiveness of the MI group compared with UC by estimating the probability of recurrent stroke based on their SBP and LDL-cholesterol levels at 12 months poststroke. Modeling will be used to extrapolate resource usage (given health services usage and health status) and evaluated over the lifetime of the cohort. Probabilistic sensitivity (using Monte Carlo simulations) analysis will be conducted to reflect the combined implications of uncertainty in the model parameters. Further threshold analysis will be performed to identify under what conditions MI treatment poststroke could be cost effective.

\section{Study organization and funding}

The study is hosted at the National Institute for Stroke and Applied Neurosciences at AUT University, Auckland New Zealand. The research is funded by the Health Research Council of New Zealand.

\section{Summary}

The MIST study is a randomized clinical trial designed to test the effectiveness of MI for the secondary prevention of stroke. To the best of our knowledge, this is one of the largest clinical trials of MI to be carried out at a population level. This intervention has the potential benefits of being adapted in the community as a cost effective means of reducing stroke burden. In addressing the values and goals of individuals after stroke, MI may present a multifactorial approach to concomitant reduction of risk factors.

\section{Acknowledgements}

The authors wish to acknowledge the contribution of the trial participants, the ARCOS IV and MIST study RAs, and medical staff at all the Auckland and Waikato DHBs.

\section{References}

1 Talelli P, Greenwood RJ, Talelli P, Greenwood RJ. Recurrent stroke: where do we stand with the secondary prevention of noncardioembolic ischaemic strokes? Ther Adv Cardiovasc Dis [Review] . 2008; 2:387-405.

2 Hankey GJ, Hankey GJ. Secondary prevention of recurrent stroke. Stroke [Review]. 2005; 36:218-21.

3 Diener HC, Weimar C, Diener H-C, Weimar C. Update of secondary stroke prevention. Nephrol Dial Transplant [Editorial Research Support, N.I.H., Extramural Non-U.S. Gov't Review]. 2009; 24:1718-24.

4 Pendlebury ST, Rothwell PM, Pendlebury ST, Rothwell PM. Risk of recurrent stroke, other vascular events and dementia after transient ischaemic attack and stroke. Cerebrovasc Dis [Research Support, NonU.S. Gov't Review]. 2009; 27(Suppl. 3):1-11.

5 Boysen G, Truelsen T. Prevention of recurrent stroke. Neurol Sci [Review]. 2000; 21:67-72.

6 Hardie K, Hankey GJ, Jamrozik K, Broadhurst RJ, Anderson C. Tenyear risk of first recurrent stroke and disability after first-ever stroke in the Perth Community Stroke Study. Stroke 2004; 35:731-5.
7 Phillips RA, Phillips RA. A review of therapeutic strategies for risk reduction of recurrent stroke. Prog Cardiovasc Dis [Research Support, Non-U.S. Gov't Review]. 2008; 50:264-73.

8 Graham GD, Graham GD. Secondary stroke prevention: from guidelines to clinical practice. J Natl Med Assoc [Research Support, Non-U.S. Gov't Review]. 2008; 100:1125-37.

9 Bushnell CD, Colon-Emeric CS, Bushnell CD, Colon-Emeric CS. Secondary stroke prevention strategies for the oldest patients: possibilities and challenges. Drugs Aging [Research Support, Non-U.S. Gov't Review]. 2009; 26:209-30.

10 Sacco RL, Adams R, Albers G et al. Guidelines for prevention of stroke in patients with ischemic stroke or transient ischemic attack: a statement for healthcare professionals from the American Heart Association/American Stroke Association Council on Stroke: co-sponsored by the Council on Cardiovascular Radiology and Intervention: the American Academy of Neurology affirms the value of this guideline. Circulation [Practice Guideline]. 2006; 113:e409-49.

11 Cuddy MLS. Treatment of hypertension: guidelines from JNC 7 (the seventh report of the Joint National Committee on Prevention, Detection, Evaluation, and Treatment of High Blood Pressure 1). J Pract Nurs 2005; 55:17-21; quiz 2-3.

12 O’Donnell MJ, Xavier D, Liu L et al. Risk factors for ischaemic and intracerebral haemorrhagic stroke in 22 countries (the INTERSTROKE study): a case-control study. Lancet [Multicenter Study Research Support, Non-U.S. Gov't]. 2010; 376:112-23.

13 Wolf PA, Clagett GP, Easton JD et al. Preventing ischemic stroke in patients with prior stroke and transient ischemic attack: a statement for healthcare professionals from the stroke council of the American Heart Association. Stroke 1999; 30:1991-4.

14 Cupples ME, McKnight A. Randomised controlled trial of health promotion in general practice for patients at high cardiovascular risk. BMJ [Clinical Trial Randomized Controlled Trial Research Support, Non-U.S. Gov't]. 1994; 309:993-6.

15 Smith J, Forster A, Young J, Cochrane Group for information provision after s. Cochrane review: information provision for stroke patients and their caregivers. Clin Rehabil [Research Support, NonU.S. Gov't Review]. 2009; 23:195-206.

16 Campbell NC, Thain J, Deans HG, Ritchie LD, Rawles JM, Squair JL. Secondary prevention clinics for coronary heart disease: randomised trial of effect on health. BMJ [Clinical Trial Randomized Controlled Trial Research Support, Non-U.S. Gov't]. 1998; 316:1434-7.

17 Delaney EK, Murchie P, Lee AJ, Ritchie LD, Campbell NC. Secondary prevention clinics for coronary heart disease: a 10-year follow-up of a randomised controlled trial in primary care. Heart [Evaluation Studies Multicenter Study]. 2008; 94:1419-23.

18 Jolly K, Bradley F, Sharp S et al. Randomised controlled trial of follow up care in general practice of patients with myocardial infarction and angina: final results of the Southampton heart integrated care project (SHIP). The SHIP Collaborative Group. BMJ [Clinical Trial Randomized Controlled Trial Research Support, Non-U.S. Gov't]. 1999; 318:706-11.

19 Ellis G, Rodger J, McAlpine C et al. The impact of stroke nurse specialist input on risk factor modification: a randomised controlled trial. Age Ageing [Clinical Trial Randomized Controlled Trial Research Support, Non-U.S. Gov't]. 2005; 34:389-92.

20 Redfern J, Rudd AD, Wolfe CD et al. Stop Stroke: development of an innovative intervention to improve risk factor management after stroke. Patient Educ Couns [Evaluation Studies Research Support, Non-U.S. Gov't]. 2008; 72:201-9.

21 Ovbiagele B, Saver JL, Fredieu A et al. PROTECT: a coordinated stroke treatment program to prevent recurrent thromboembolic events. Neurology [Research Support, N.I.H., Extramural Research Support, Non-U.S. Gov't Research Support, U.S. Gov't, P.H.S.]. 2004; 63:121722.

22 LaBresh KA, Ellrodt AG, Gliklich R et al. Get with the guidelines for cardiovascular secondary prevention: pilot results. Arch Intern Med [Research Support, Non-U.S. Gov't]. 2004; 164:203-9. 
23 Lawrence M, Kerr S, McVey C, Godwin J. The effectiveness of secondary prevention lifestyle interventions designed to change lifestyle behavior following stroke: summary of a systematic review. Int J Stroke [Research Support, Non-U.S. Gov't Review]. 2012; 7:243-7.

24 Ovbiagele B, Campbell S, Faiz A, Chambless LE, Investigators VS. Relationship between non-specific prescription pill adherence and ischemic stroke outcomes. Cerebrovasc Dis [Multicenter Study Randomized Controlled Trial Research Support, N.I.H., Extramural]. 2010 Jan;29:146-53.

25 Brown MT, Bussell JK. Medication adherence: WHO cares? Mayo Clin Proc 2011; 86:304-14.

26 Sabaté E (ed.). Adherence to Long-Term Therapies: Evidence for Action. Geneva, Switzerland, World Health Organization, 2003.

27 Group NZG. Life after Stroke. New Zealand Guideline for Management of Stroke. Wellington, Stroke Foundation New Zealand Inc., 2003.

28 Aspegren K, Risager NE, Stromming M. Learning 'The Motivational Interview' in a simple way. Ugeskr Laeger 2008; 170:39-43.

29 Castro MMLD, Passos SRL. Motivational interview and scales used to assess the degree of motivation for treatment in drug abuse patients. Rev Psiquiatr Clín 2005; 32:330-5.

30 Florez-Alarcon L, Carranza WA. The motivational interview as a tool for encouraging lifestyle changes in people with chronic non transmittable diseases. Av Piscol Clin Latinonot 2007; 25:63-82.

31 Lussier MT, Richard C. The motivational interview: in practice. Can Fam Physician 2007; 53:2117-8.

32 Miller RW, Rollnick S. Motivational Interviewing: Preparing People to Change Addictive Behavior. New York, NY, The Guilford Press, 1991.

33 Rollnick S, Mason P, Butler C. Health Behavior Change: A Guide for Practitioners. New York, NY, Churchill Livingstone, 2000.

34 Heather N. Motivational interviewing: effectiveness and costeffectiveness. Addiction 2001; 96:1772-3.

35 Stein LAR, Lebeau R, Colby SM, Barnett NP, Golembeske C, Monti PM. Motivational interviewing for incarcerated adolescents: effects of depressive symptoms on reducing alcohol and marijuana use after release. J Stud Alcohol [Comparative Study Randomized Controlled Trial Research Support, N.I.H., Extramural]. 2011; 72:497-506.

36 Smith AJ, Shepherd JP, Hodgson RJ. Brief interventions for patients with alcohol-related trauma. Br J Oral Maxillofac Surg [Research Support, Non-U.S. Gov't Review]. 1998; 36:408-15.

37 Baker A, Lewin T, Reichler $\mathrm{H}$ et al. Evaluation of a motivational interview for substance use within psychiatric in-patient services. Addiction [Clinical Trial Randomized Controlled Trial Research Support, NonU.S. Gov't]. 2002; 97:1329-37.

38 Murphy JG, Benson TA, Vuchinich RE et al. A comparison of personalized feedback for college student drinkers delivered with and without a motivational interview. J Stud Alcohol [Clinical Trial Comparative Study Randomized Controlled Trial Research Support, U.S. Gov't, Non-P.H.S.]. 2004; 65:200-3.

39 Lussier MT, Richard C, Lussier M-T, Richard C. The motivational interview: in practice. Can Fam Physician 2007; 53:2117-8.

40 Rivera Mercado S, Villouta Cassinelli MF, Ilabaca Grez A, Rivera Mercado S, Villouta Cassinelli MF, Ilabaca Grez A. [Motivational interviews: what are their effectiveness in prevalent primary care problems?]. Aten Primaria 2008; 40:257-61.

41 Dunn C, DeRoo L, Rivara FP. The use of brief interventions adapted from motivational interviewing across behavioral domains: a systematic review. Addiction 2001; 96:1725-42.

42 Miller WR, Rollnick S. Motivational Interviewing: Preparing People for Change, 2nd edn. New York, Guilford Press, 2002.

43 Watkins CL, Auton MF, Deans CF et al. Motivational interviewing early after acute stroke: a randomized, controlled trial. Stroke [Comparative Study Randomized Controlled Trial Research Support, NonU.S. Gov't]. 2007; 38:1004-9.
44 Leathley MJ, Fall S, Sharma AK, Watkins C, Barer D. Life after stroke [abstract]: multi-centre trial of psychosocial interventions after stroke. Cerebrovasc Dis 2003; 16(Suppl. 4):70.

45 Lincoln NB, Flannaghan T. Cognitive behavioral psychotherapy for depression following stroke: a randomized controlled trial. Stroke [Clinical Trial Randomized Controlled Trial Research Support, NonU.S. Gov't]. 2003; 34:111-5.

46 Dennis M, O’Rourke S, Slattery J, Staniforth T, Warlow C. Evaluation of a stroke family care worker: results of a randomised controlled trial. BMJ [Clinical Trial Randomized Controlled Trial]. 1997; 314:1071-6. discussion 6-7.

47 Forster A, Young J. Specialist nurse support for patients with stroke in the community: a randomised controlled trial. BMJ 1996; 312:1642-6.

48 Bombardier CH, Bell KR, Temkin NR et al. The efficacy of a scheduled telephone intervention for ameliorating depressive symptoms during the first year after traumatic brain injury. J Head Trauma Rehabil [Randomized Controlled Trial Research Support, Non-U.S. Gov't]. 2009; 24:230-8.

49 Woollard J, Beilin L, Lord T, Puddey I, MacAdam D, Rouse I. A controlled trial of nurse counselling on lifestyle change for hypertensives treated in general practice: preliminary results. Clin Exp Pharmacol Physiol [Clinical Trial Randomized Controlled Trial Research Support, Non-U.S. Gov't]. 1995; 22:466-8.

50 Reid CM, Murphy B, Murphy M, Maher T, Ruth D, Jennings G. Prescribing medication versus promoting behavioural change: a trial of the use of lifestyle management to replace drug treatment of hypertension in general practice. Behav Change 1994; 11:177-85.

51 Groeneveld IF, Proper KI, Van Der Beek AJ, Van Duivenbooden C, Van Mechelen W. Design of a RCT evaluating the (cost-) effectiveness of a lifestyle intervention for male construction workers at risk for cardiovascular disease: the health under construction study. BMC Public Health 2008; 8:1. doi: 10.1186/1471-2458-8-1.

52 Longabaugh R. Comments on Dunn et al.'s 'The use of brief interventions adapted from motivational interviews across behavioral domains: a systematic review'. Why is motivational interviewing effective? Addiction [Comment]. 2001; 96:1773-4. discussion 4-5.

53 Krishnamurthi R, Jones A, Barber A et al. Methodology of a population-based stroke and TIA incidence and outcomes study: the Auckland Regional Community Stroke Study (ARCOS IV) 20112012. Int J Stroke 2013; DOI: 10.1111/ijs.12108.

54 Aho K, Harmsen P, Hatano S, Marquardsen J, Smirnov VE, Strasser T. Cerebrovascular disease in the community: results of a WHO collaborative study. Bull World Health Organ 1980; 58:113-30.

55 Sterne JAC, White IR, Carlin JB et al. Multiple imputation for missing data in epidemiological and clinical research: potential and pitfalls. $B M J$ [Research Support, Non-U.S. Gov't]. 2009; 338:b2393.

56 Ware JE, Kosinski M, Keller SD. SF-36 Physical and Mental Health Summary Scales: A Users Manual. Boston, The Health Institute, New England Medical Centre, 1994.

57 Johnston M, Pollard B, Hennessey P. Construct validation of the hospital anxiety and depression scale with clinical populations. J Psychosom Res 2000; 48:579-84.

58 Sulter G, Steen C, De KJ. Use of the Barthel index and modified Rankin scale in acute stroke trials. Stroke 1999; 30:1538-41.

\section{Supporting Information}

Additional Supporting Information may be found in the online version of this article at the publisher's web-site:

Appendix S1. MIST Data Safety Monitoring Committee and ARCOS IV Steering Committee 